\title{
Victim prevalence in bullying and its association with teacher-student and student-student relationships and class moral disengagement: $A$ class-level path analysis
}

Robert Thornberg, Linda Wänström, Tiziana Pozzoli and Gini Gianluca

The self-archived postprint version of this journal article is available at Linköping University Institutional Repository (DiVA):

http:/ / urn.kb.se/ resolve?urn=urn:nbn:se:liu:diva-135448

N.B.: When citing this work, cite the original publication.

This is an electronic version of an article published in:

Thornberg, R., Wänström, L., Pozzoli, T., Gianluca, G., (2018), Victim prevalence in bullying and its association with teacher- student and student- student relationships and class moral disengagement: A class-level path analysis, Research Papers in Education, 33(3), 320-335.

https:// doi.org/ 10.1080/ 02671522.2017.1302499

Original publication available at:

https:/ / doi.org/ 10.1080/02671522.2017.1302499

Copyright: Taylor \& Francis (Routledge) (SSH Titles)

http:// www.routledge.com/ 


\section{Victim Prevalence in Bullying and its Association with Teacher- \\ Student and Student-Student Relationships and Class Moral \\ Disengagement: A Class Level Path Analysis}

Robert Thornberg

Department of Behavioural Sciences and Learning, Linköping University, Linköping, Sweden

Linda Wänström

Department of Computer and Information Science, Linköping University, Linköping, Sweden

Tiziana Pozzoli

Department of Development and Social Psychology, University of Padua, Padua, Italy

Gianluca Gini

Department of Development and Social Psychology, University of Padua, Padua, Italy

\section{Acknowledgments}

This research was partially supported by a grant awarded to Robert Thornberg from The Swedish Research Council (D0775301).

\section{Conflict of Interest}

The authors declare that they have no conflict of interest.

Corresponding author: Robert Thornberg, PhD, Professor, phone: 4613 282118, e-mail: robert.thornberg@liu.se, address: Department of Behavioural Sciences and Learning, Linköping University, SE-58183 Linköping, SWEDEN 


\section{Victim Prevalence in Bullying and its Association with Teacher- Student and Student-Student Relationships and Class Moral Disengagement: A Class Level Path Analysis}

The aim of the present study was to test whether teacher-student relationship quality and student-student relationship quality at class level and class moral disengagement, considered together in a single model, were related to class prevalence of victims of bullying. A sample of 899 Swedish children was recruited from 43 elementary school classes. The participants filled out a questionnaire. Because the focus of the present study was on class behaviours, all analyses were conducted on aggregated class level data. A path analysis revealed that the prevalence of victims was likely to be lower in classes with more positive teacher-student and student-student relationships and lower levels of class moral disengagement. Teacher-student relationship quality was not directly linked to class prevalence of victims, but indirectly through its direct association with student-student relationship quality. Student-student relationship quality was negatively associated with class moral disengagement and both were directly related to class prevalence of victims. Results suggest that caring, supportive and warm student-student relationships in the class should be considered as a crucial protective factor against bullying victimization. Further, the findings suggest that class moral disengagement has to be addressed in bullying prevention.

Keywords: bullying; victimization; teacher-student relationships; student-student relationships; class moral disengagement

Subject classification codes: include these here if the journal requires them

\section{Introduction}

The social-ecological framework states that the prevalence of victims of bullying has to be understood as an ecological phenomenon where contextual variables, such as teacher-student relationships and the peer ecology at class level, play an important role (Espelage and Swearer 2004; Hong and Espelage 2012). According to Hong and 
Espelage (2012), 'the most direct influences in bullying behavior among youth are within microsystem, which is composed of individuals or groups of individuals within immediate settings (e.g., home, school) with whom youth have interactions’ (315). In the current study, we have conducted a microsystem level analysis by focusing on the most significant microsystem within the school context that elementary students have daily contact with, namely the school class.

Because bullying refers to repeated inhumane actions intended to harm and directed at individuals who are disadvantaged or less powerful in these social interactions (e.g. Olweus 2010), it represents a serious moral transgression in school (Hymel et al. 2010), which students in general recognize (Maunder, Harrop, and Tattersall 2010; Thornberg et al. 2016). In the current study, we have focused on three moral dimensions of the class microsystem that are likely to influence the prevalence of victims of bullying in school classes, namely the quality of classroom teacher-student relationships, the quality of student-student relationships in the class (henceforth, teacher-student relationships and student-student relationships, respectively), and class moral disengagement, that is, the degree of moral disengagement processes at the class level.

Bullying is a group phenomenon among students (Salmivalli 2010) and it is a part of the peer ecology of the school class (Saarento and Salmivalli 2015). Therefore, since the quality of student-student relationships in the school class and the class moral disengagement are components of the group characteristics of the school class, we assumed them to be directly linked to the prevalence of bullying victimization when concurrently included in a single model. In contrast, the quality of classroom teacherstudent relationships is not part of the peer ecology but has the ability to influence the moral atmosphere of the peer ecology (Jennings and Greenberg 2009; Noddings 2012; 
Nucci and Narvaez 2008; Wentzel 2015). Therefore, we assumed it to be directly linked to the quality of student-student relationships in the class and the class moral disengagement and, through them, indirectly associated with the prevalence of bullying victimization in the class.

\section{Class relational climate: Teacher-student and student-student relationships}

Several studies in different fields have underlined the significant impact of the quality of relationships at school on students' beliefs, attitudes and behaviours (e.g. Hamre and Pianta, 2006; McGrath and Van Bergen 2015; Power and HigginsD’Alessandro 2008; Wubbels et al. 2015). The most important relationships within the school context are certainly represented by teacher-student and student-student relationships (Eliot et al. 2010). When these relationships are characterized by caring, supportive, fair and respectful interaction patterns, they contribute to creating a positive relational climate within school that, in turn, affects students' lives.

For example, a robust body of research has shown positive, warm and supportive teacher-student relationships to be positively linked with students’ academic engagement and achievement (for a meta-analysis, see Roorda et al. 2011), particularly among at-risk students (for a review, see Sabol and Pianta 2012), students with learning difficulties, ethnic minority students, and students with a low SES (Roorda et al. 2011). In addition to academic engagement and achievement, there is a growing body of research revealing that teachers can make crucial contributions to students' emotional and social development and behaviours (Jennings and Greenberg 2009). In their review, Jennings and Greenberg (2009) conclude that healthy and supportive teacher-student relationships provide the keystone to effective classroom management and a prosocial classroom climate. Through these secure relationships, students learn about socially appropriate behaviours as well as academic expectations and how to achieve these 
expectations (Hamre and Pianta 2001). In schools and classes in which teachers are caring, respectful and supportive, students report higher psychological well-being (Sarkova et al. 2014) and higher degrees of peer acceptance (Hughes, Cavell, and Wilson 2001; Hughes, Myung, and Wehrly 2014), and are less engaged in oppositional and antisocial behaviour (Bru, Stephens, and Torsheim 2002; Hamre et al. 2008; Maldonado-Carrenño and Votruba-Drzal 2011; Richard, Schneider, and Mallet 2011; Rey et al. 2007), including bullying (Gregory et al. 2010; Richard, Schneider, and Mallet 2011). In line with these results and adopting a social-ecological framework, Hughes, Myung and Wehrly (2014) argue that 'as chief architects and managers of classroom contexts, teachers exert considerable influence on the classroom peer ecology’ (309).

Similarly to teacher-student relationships, the quality of student-student relationships is often associated with positive outcomes in students' lives and school adjustment. Perceived quality of student-student relationships, for example in terms of high levels of support, has been found to influence students' motivations and behaviours (Isakson and Jarvis 1999; Rosenfeld, Richman, and Bowen 1998), including psychological well-being (Sarkova et al. 2014). Moreover, there is a plethora of research on both the negative impact of maladaptive and antisocial behaviour of peers, as well as the influence of peers on prosocial and positive behaviours (e.g. Brechwald and Prinstein 2011; Brown and Klute 2006).

Concerning the relationship between the two components of class relational climate, previous studies have revealed a positive association between teacher-student relationships and student-student relationships (Matsumura, Slater, and Crosson 2008; Rey et al. 2007). The presence of caring and supportive teachers can indeed improve the quality of student-student relationships, for example by enhancing students' sense of 
class membership and reducing peer conflicts. In this respect, Solomon et al. (1996) found that teacher supportiveness was associated with more positive behaviour in the class and positive perceptions of students' connectedness. Moreover, several researchers have suggested that the concurrent association between teacher-student support and peer support, for example, is explained by children's use of information about teacherstudent interactions in forming opinions about a classmate (e.g., Hughes, Cavell, and Wilson 2001; Hymel 1986). In other words, teachers who value and demonstrate caring and respect towards students may create a class environment in which students behave appropriately because they care about each other, rather than because they fear the consequences of rule breaking (Orpinas and Horne 2010).

More interesting for the purpose of this study are the relationships between relational climate and bullying at school. Overall, a negative relational climate within the school class has been associated with increased risks of bullying behaviours (Espelage and Swearer 2010). The findings of previous studies showed that teachers' interactions with students can affect classmates' perceptions of individual students, in turn affecting which students the classmates choose to interact with and accept (Howes, Hamilton, and Matheson 1994; Hughes, Cavell, and Jackson 1999). Thus, conflicting interactions between teachers and students may convey a lack of acceptance, causing other students to also reject the student involved in the conflict with the teacher (Hughes et al., 1999).

Negative student-student relationships may be a proximal risk factor for victimization. Previous studies found that victims report poor peer relationships, characterized by low peer acceptance, support, friendship and reciprocity (Demaray and Malecki 2003; Perren and Alasker 2006; Perren and Hornung 2005; Rigby 2000). In addition, other findings suggested that perceived peer social support and positive 
friendship/relationships can serve as effective buffers against peer victimization and reduce the negative effects of bullying on students' quality of life (Bollmer et al. 2005; Flaspohler, Elfstrom, Vanderzee, and Sink 2009; Schmidt and Bagwell 2007).

Despite the attention paid to the quality of relationships at school in the bullying literature, a possible limitation of the extant research is that the negative association between the quality of relationships and bullying has usually been examined at either the whole school level (e.g. Gregory et al. 2010; Richard, Schneider, and Mallet 2011) or, more frequently, the individual level (e.g. Casas, Ortega-Ruiz and Del Rey 2015; Raskauskas et al. 2010). However, with respect to the analysis of contextual influences on bullying, there are at least two reasons for considering the school class as the most relevant microsystem (Pozzoli, Gini, and Vieno 2012). Firstly, it is well known that bullying significantly varies across school classes (Atria, Strohmeier, and Spiel 2007), and several authors agree that school classes represent an important context for both understanding and handling this phenomenon (e.g. Doll, Song, and Siemers 2004; Salmivalli and Voeten 2004). Secondly, in Sweden, as well as in other countries, elementary school students remain most often in a single school class with the same classmates for the full school-day and for more than one year. Therefore, investigating the quality of teacher-student and student-student relationships - here defined as the degree of warmth, caring, supportiveness and respectfulness interaction pattern and relationship-building at class level - should be crucial to understanding class variability in bullying victimization.

In line with previous research (Matsumura, Slater, and Crosson 2008; Rey et al. 2007), we hypothesized that the quality of teacher-student relationships would be directly and positively associated with the quality of student-student relationships. We assumed that caring, warm and supportive teacher-student relationships would be 
linked with caring, warm and supportive student-student relationships that, in turn, would be directly linked to the prevalence of victims of bullying in the class. Stefanek, Strohmeier, van de Schoot and Spiel (2011) found the quality of student-student relationships to be negatively associated with peer victimization at class level. However, they stated that 'we did not look at teacher behavior in our study, we therefore recommend considering teacher behaviors in future studies' (81), which is what we did in the present study.

\section{Class Moral Disengagement}

In harmony with the social-ecological framework, Bandura’s (1986, 1997, 1999, 2002) social-cognitive theory states that moral agency has to be understood as situated and learned through the environment and culture in which people establish their social relationships. Further, Bandura (1999, 2002) introduced the concept of moral disengagement to refer to a set of self-serving cognitive distortions by which selfregulated mechanisms can be deactivated and moral self-sanctions can be disengaged, in turn promoting or facilitating inhumane behaviour. Examples of moral disengagement mechanisms are using worthy ends or moral purposes to excuse pernicious means (moral justification), diluting personal responsibility because other people are also involved (diffusion of responsibility), disregarding or distorting the negative or harmful consequences of the actions, and believing that the victim deserves his or her suffering (blaming the victim). (See Bandura [2002] for a more detailed description.) So far, the association between moral disengagement and bullying has been mainly investigated at the individual level, showing that bullying behaviour, as well as general aggression, is positively related to moral disengagement (for a metaanalysis, see Gini, Pozzoli, and Hymel 2014). 
Even though Bandura (1999, 2002) underlines the importance of the context and the interplay between individual and situational factors in understanding cognition and behaviour, and other authors agree that moral disengagement can also be considered a characteristic of the group (Hymel et al. 2010), only a few studies have examined whether moral disengagement at the class level might contribute to explaining the variation between classes of aggression and bullying. One study (Pozzoli, Gini, and Vieno 2012) found that class moral disengagement significantly explained betweenclass variability in pro-bullying behaviour, which was a composite behavioural index of bullying, assisting bullies and reinforcing bullying behaviour. Moreover, a more recent study has shown that the degree of classroom collective moral disengagement explains between-class variability in peer aggression (Gini, Pozzoli, and Bussey 2015). These results are consistent with social psychological theories of group functioning (Crano 2000). School classes, like other social groups, are indeed characterized by social norms and moral climate. These characteristics may confer varying levels of approval toward negative conducts, thereby affecting the behaviour of group members even when they do not reflect their private attitudes (e.g., Espelage, Holt, and Henkel 2003; Juvonen and Galvan 2008). Group decision-making can facilitate inhumane behaviour by virtue of the responsibility being shifted to the group as opposed to the individual. For example, it has been demonstrated that people have an increased likelihood of behaving more cruelly in a group as opposed to when they are alone, or when the victimized person or group is perceived as sub-human by the other group members (Diener 1979; Haslam 2006).

Consistently with Pozzoli, Gini, and Vieno’s (2012) approach, class moral disengagement has been adopted in the present study by aggregating individual moral disengagement at the class level (i.e., the class mean of individual moral disengagement 
scores). In addition to the expected positive link between class moral disengagement and class prevalence of victims, we hypothesized class moral disengagement to be negatively associated with teacher-student relationship quality and student-student relationship quality. A warm, supportive, caring and respectful relationship and interaction pattern among the classmates should lower the risk of class moral disengagement, and both these socio-moral peer ecology factors of the school class should contribute to explaining the between-class variability in victims of bullying.

\section{The Present Study}

To sum up, in line with the social-ecological framework, the goal of the present study was to understand the prevalence of victims of bullying within school classes as a characteristic of the peer ecology of the class embedded in the overall school context. In this context, bullying occurs mostly far away from the classroom and when teachers are not present (Craig and Pepler 1997; Craig, Pepler, and Atlas 2000; O’Connell, Pepler, and Craig 1999), including in Sweden (Osbeck, Holm, and Wernersson 2003).

Therefore, we assumed the teacher-student relationship quality to be indirectly and negatively related to victimization through its influences on the group characteristics of the school class. More precisely, the aim of the present study was to test at class level (a) whether teacher-student relationship quality was related to student-student relationship quality and class moral disengagement, (b) whether student-student relationship quality was related to class moral disengagement, and (c) whether studentstudent relationship quality and class moral disengagement were uniquely related to class prevalence of victims of bullying. Because the focus of the present study was exclusively on class-level phenomenon, the unit of interest was the school class. We hypothesized that teacher-student relationship quality would be positively associated with student-student relationship quality and negatively associated with class moral 
disengagement. We also hypothesized student-student relationship quality to be negatively associated with class moral disengagement. Finally, we hypothesized that fewer students would be victims in school classes characterized by positive (caring, warm and supportive) student-student relationships and lower levels of class moral disengagement.

\section{Method}

\section{Participants}

Participants in the study were recruited from 43 elementary school classes (grades 4-6) at 15 public schools located in two small villages in the countryside and in different areas of two midsized cities in Sweden. Class sizes ranged from 14 to 28 students $(M=20.93, S D=3.60)$. In elementary school (grades $1-6)$, students have a home classroom in which most of their classes take place, and they have the same class teacher in most school subjects. This teacher usually follows them through grades 1-3, and then a new teacher follows them through grades 4-6.

The original sample consisted of 996 students, but 95 of them (10\%) did not participate due to different reasons. Parental consent was required for participation. Some parents and students declined, and other students were absent because of sickness or other reasons unknown at the time of data collection. In addition, two students were excluded from subsequent analyses because they had missing scores on class relational climate. Thus, the final sample consisted of 899 students (435 girls and 464 boys; age range 9-13 years old; $M=11.00, S D=.83)$. Socioeconomic status was not directly measured in the study, but the sample of public schools represented a wide range of sociogeographic locations and socioeconomic statuses. Most participants had a Swedish ethnic background, and only a small minority (16\%) had an immigrant background - 
that is, they were born in another country or at least one of their parents was born in another country.

\section{Procedure}

Participants were given a questionnaire and filled it out in their ordinary classroom setting. Five student teachers at the end of their teacher training were present in the classrooms during the data collection (one student teacher in each classroom). They explained the study procedure, assured students of confidentiality, and assisted the participants who needed help. The student teachers had received instructions and training from the first author. The participants responded to the questionnaire anonymously.

\section{Measures}

The questionnaire started with a few background questions concerning age (grand mean centred in the analysis), gender ( 0 = girl, $1=$ boy) and ethnic background ( 0 = Swedish ethnic background, 1 = immigrant ethnic background), followed by a bullying victimization scale, a moral disengagement scale and a class relational climate scale.

Victimization. A five-item scale was developed to measure victimization (Thornberg, Wänström, and Pozzoli 2016). The participants were presented with a list of behavioural items and asked to rate "How often has this happened at school in the past three months?” The items were "I’ve been teased by one or more students”, "I’ve been beaten by one or more students”, “Students have excluded me from the group”, “One or more students spread mean rumours about me” and "I’ve been threatened by one or more students.” The participants indicated how often they had been victims of the behaviour described in each item on a five-point scale $(1=$ "Never happened", 2 = 
“A couple of times”, $3=$ " 2 or 3 times a month", 4 = “About once a week” and $5=$ “Several times a week") (Cronbach's $\alpha=.83$ ). The response "About once a week” was used as the cut-off point (cf. Solberg and Olweus 2002), that is, participants who reported being victimized about once a week or more often in at least one of the five items were considered as victims of bullying in the paper. The class prevalence of victims was then computed as the proportion of victims in the class (number of victims divided by the total number of students in the class) ${ }^{1}$.

Class Moral Disengagement. A six-item moral disengagement in bullying scale was used to measure participants’ proneness to morally disengage in bullying situations in which a definition of bullying was first provided (Thornberg and Jungert 2013; e.g. “Bullying is okay in certain cases”, “Some people deserve to be bullied”). Participants rated each item on a seven-point scale ( $1=$ "Disagree”, 7 = “Agree”). The average of these six items was computed for each student (Cronbach's $\alpha=.80$ ). Class moral disengagement was then computed as the (centred) class average.

Class Relational Climate Scale. We adopted a 23-item scale (Thornberg, Wänström, and Pozzoli 2016) to measure the class relational climate (i.e., the quality of the social relationship and interaction patterns of each school class) by examining the classroom teacher-student relationship quality and the student-student relationship

1 When victimization is adopted as a continuous variable, i.e., the mean from a victimization scale, the analysis would not make a distinction between those who are bullied and those who are occasionally peer victimized. In the current study, we have analysed individual victimization as a categorical variable (being victimized by peers at least once a week) in order to identify those who are bullied considering the criterion of repetition (cf. Solberg and Olweus 2002), and examined associations between microsystem factors and prevalence of victims of bullying at class level. 
quality in the class, in which high quality was conceptualized as warm, caring, supportive, friendly and respectful relationships. Participants rated each item on a fourpoint scale ( 1 = disagree, 4 = agree). Fifteen items were used to measure participants' perceptions of the teacher-student relationship quality (e.g. "The teachers listen to the students when they have problems”, "Our teachers really care about the students”; Cronbach's $\alpha=.90$ ) and eight items to measure their perceptions of the student-student relationship quality (e.g. “The students are kind and nice to each other in our class”, "We care about each other in our class" and "There are lots of conflicts between the students in our class" [rev.]; Cronbach's $\alpha=.88$ ). Averages of these two sub constructs were computed for each student and scores were grand mean centred. Teacher-student and student-student relationship qualities were then computed as the (centred) class averages.

\section{Statistical Model}

In order to estimate both direct and indirect effects on class prevalence of victims (CPV), a path model including the variables teacher-student relationships (TSR), student-student relationships (SSR) and class moral disengagement (CMD) was analysed through structural equation analysis. The following equations were estimated simultaneously through maximum likelihood using Proc Calis in SAS:

$$
\begin{aligned}
& C P V=\lambda_{1} C M D+\lambda_{2} S S R+\varepsilon_{1}, \\
& C M D=\lambda_{3} S S R+\lambda_{4} T S R+\varepsilon_{2}, \\
& S S R=\lambda_{5} T S R+\varepsilon_{3},
\end{aligned}
$$

where $\lambda_{1}$ to $\lambda_{5}$ are factor loadings and $\varepsilon_{1}$ to $\varepsilon_{3}$ are error terms. Because of the exclusive focus on class-level phenomenon, all individual-level variables were aggregated to the class level using mean scores or percentage scores. Similar to how 
Donohue, Perry, and Weinstein (2003) argued, by allowing the percentages of victims to vary from school class to school class, we were able to analyse victimization as "a group-level and context-specific phenomenon, precisely where it is most likely to occur for school-age children” (p. 114), namely the school class. If we had instead been interested in the individual level victimization (victimized vs non-victimized), the natural statistical analysis would have been to estimate a multilevel logistic regression. However, because our interest was exclusively on between-class variation of group characteristics and our response variable thus was on school class level, a multilevel model was not appropriate to use in our case.

\section{Results}

\section{Descriptive Statistics and Correlations}

Table 1 shows descriptive statistics for and correlations between class-level variables. The Pearson correlation matrix showed that teacher-student relationship quality was positively correlated with student-student relationship quality and negatively correlated with prevalence of victims. Student-student relationship quality was negatively correlated with class moral disengagement and prevalence of victims. Finally, class moral disengagement was positively correlated with prevalence of victims.

$$
\text { - insert Table } 1 \text { about here - }
$$

\section{Path Analysis}

The model in Figure 1 was estimated through structural equation modelling using Proc Calis in SAS. Because the bivariate correlation between teacher-student relationship quality and prevalence of victims was significant (see Table 1), a model 
with a direct path between these two variables was also estimated. In line with our original hypothetical model (Fig. 1), this path was not significant and therefore dropped. In contrast to our hypothetical model, the direct path between teacher-student relationship quality and class moral disengagement was not statistically significant, and the model was re-estimated with this path removed. Results indicate good fit of the model: $\chi^{2}(2)=1.286 ;$ GFI $=.99 ;$ NFI $=.98 ;$ RMSEA $=.000$ (90\% C.I.: .000; .2686). Path estimates (factor loadings) are shown in Figure 2. Teacher-student relationship quality, student-student relationship quality and class moral disengagement together explain $56.32 \%$ of the variance in class prevalence of victims.

- insert Figure 2 about here -

Results indicated that positive (caring, warm and supportive) teacher-student relationships were associated with positive student-student relationships, which in turn were linked with lower levels of class moral disengagement. Student-student relationship quality and class moral disengagement, in turn, contributed to explaining the prevalence of victims. Thus, the findings revealed that teacher-student relationship quality was associated with prevalence of victims, but that the relationship was not direct but indirect via the socio-moral climate of the peer group constituting the class. Higher student-student relationship quality and lower levels of class moral disengagement were associated with lower prevalence of victims.

\section{Discussion}

The present study is the first to test the role of teacher-student relationship quality, student-student relationship quality and class moral disengagement in the 
prevalence of victims of bullying at class level in a single model. As a first step, we examined the inter-class correlations between the variables, and consistent with our hypotheses, class prevalence of victims was likely to be lower in classes with positive (caring, warm and supportive) teacher-student and student-student relationships and lower levels of class moral disengagement. Because teacher-student relationship quality was significantly correlated with less prevalence of victims of bullying, we tested a model with a direct path between these two variables. As we assumed, teacher-student relationship quality was not directly associated with class prevalence of victims. Our hypothesis about the indirect link between quality of teacher-student relationships and class prevalence of victims of bullying via student-student relationships was, nevertheless, supported by the final model in the present findings. Thus, one of the main results of the present study was to reveal that school classes that had more caring, warm and supportive teacher-student relationships tended to be characterized by similar student-student relationships, which in turn were associated with less prevalence of victims of bullying in those classes. In addition, both the inter-class correlation analysis and the path analysis (in terms of direct vs. indirect paths) indicated that student-student relationship quality and class moral disengagement were more critical than teacherstudent relationship quality to explain the inter-class variation of prevalence of victims of bullying.

Hence, our findings shed some new light on previous research that has shown a negative association between the teacher-student relationship quality and bullying (e.g., Gregory et al. 2010; Richard, Schneider, and Mallet 2011). Our findings support Hughes, Myung, and Wehrly (2014) when they state that teachers, as chief architects and managers of classroom contexts, exert considerable influence on the classroom peer ecology, including beyond the classroom, we would add, considering that bullying most 
often takes place in the playground and in other school settings out of teachers’ surveillance (Craig and Pepler 1997; Craig, Pepler, and Atlas 2000; O’Connell, Pepler, and Craig 1999; Osbeck, Holm, and Wernersson 2003). Although teachers and students participate in the same microsystem of the classroom, teachers are not a part of the students' peer ecology. The current study highlights the importance of being aware of this ecology difference demonstrated by the indirect path (and the lack of a direct path) between teacher-student relationship quality and victim prevalence mediated by student-student relationship quality. It suggests that caring and supportive teacherstudent relationships in the classroom context appear to influence the peer ecology of the school class, not only in the classroom but also outside the classroom, which in turn seems to influence the prevalence of victims of bullying.

Another important finding in the current study was the negative association between student-student relationship quality and class moral disengagement, which suggests that class moral disengagement tends to be lower in classes with positive, caring, warm, friendly and supportive student-student relationships. However, the hypothesis about the direct link between teacher-student relationship quality and class moral disengagement was not supported. The findings suggest instead an indirect association between teacher-student relationship quality and class moral disengagement through student-student relationship quality. Thus, our findings revealed that school classes that had more caring, warm and supportive teacher-student relationships tended to be characterized by similar student-student relationships, which in turn were associated with lower levels of class moral disengagement. Further, the prevalence of victims of bullying was less in school classes characterized by higher levels of caring, warm and supportive student-student relationships and lower levels of class moral disengagement. 
In accordance with social-cognitive theory of moral agency (Bandura 1999, 2002), moral disengagement has to be understood as a situated phenomenon learned through social interactions with others. In line with the social-ecological framework, it has to be considered as a result of the complex interplay between individual and contextual factors. In contrast with most research on moral disengagement, we have studied moral disengagement as a group phenomenon by adopting the theoretical construct class moral disengagement (Pozzoli, Gini, and Vieno 2012). Qualitative studies have for example shown how students in peer groups could co-construct attributions that normalize and justify bullying, and dehumanize and blame the victims (O’Brien 2011; Teräsahjo and Salmivalli 2003; Thornberg 2015). High level of class moral disengagement creates a social environment in which the harmful intention, usually included in the traditional definition of bullying, becomes fuzzier. Other scholars focusing on the peer culture and social environment of school have also challenged the dominant focus on harmful intention to define and understand school bullying (e.g., Horton, Kvist Lindholm, and Nguyen 2015).

The present study is the first study to test whether class moral disengagement is associated with student-student relationship quality at class level, and the findings make an important contribution to our theoretical understanding of class moral disengagement. It is indeed dependent on the quality of the relationship and interaction pattern among the classmates. A more positive, caring, supportive and friendly relationship and interaction pattern among classmates seems to inhibit or counteract the degree of moral disengagement processes at the class level. For example, it is arguable that such positive student-student relationships diminish the likelihood that children will minimize or diffuse their own responsibility for negative behaviours or blame or, 
even worse, dehumanize the victim. These mechanisms, at the class level, have been shown to explain bullying behaviour (Pozzoli, Gini, and Vieno 2012).

\section{Limitations}

Some limitations of this study have to be acknowledged. Firstly, we adopted a cross-sectional design, and therefore are not able to pinpoint the direction of effects. Thus, identified associations as well as causal conclusions based on these associations should be considered with great caution. For example, although the path model suggested an influence of the classroom teacher-student relationships quality on the classroom student-student relationship quality, it might be possible that the latter influences the former, or that the influence is somewhat circular. Secondly, the victimization scale used in the current study included aggression and repetition, but did not include the power imbalance dimension inbuilt in the traditional definition of bullying (Olweus 2010). This might threaten, to some extent, the content validity and increase the risk of overrating the prevalence of victims. On the other hand, the terms 'bullying' and 'bullying victims' are value-loaded terms, which if used in the scale might increase the risk of underrating. Thus, one of the advantages with the victimization scale adopted in the current study was the avoidance of using such terms. Moreover, whereas ' 2 to 3 times a month' usually is used as the cut-off point in the literature to categorize victims (cf. Solberg and Olweus 2002; Varjas et al. 2009), 'About once a week' adopted in the current study is a stricter cut-off point of repetition, which indicates a more severe intensity of victimization. This in turn lowers the risk of overrating the prevalence of victims. Finally, a note of caution needs to be sounded regarding the generalization of the findings. This sample of students from a particular area of Sweden may or may not be similar to the population of students with whom the readers primarily work or are interested in. 


\section{Practical Implications}

Despite these limitations, the present findings have practical implications. The findings emphasize that caring, warm and supportive teacher-student relationships should be considered as an important component in bullying prevention, which might be an overlooked bullying prevention component in school principals’ and teachers' efforts to counteract bullying (cf. Corcoran and Guckin 2014). Teachers who consciously and effectively build caring and supportive relationships with their students enhance the probability of a caring and prosocial interaction and relationship pattern among the students, which in turn lowers the risk of bullying victimization among them. Thus, our findings suggest that caring, supportive and warm student-student relationships in the class should be considered as a crucial protective factor against bullying victimization, and it is important that teachers understand the association between the quality of their relationships with their students and the quality of the relationships among the students.

Further, the present study suggests that class moral disengagement has to be addressed in bullying prevention, and one way of lowering class moral disengagement appears to be to enhance caring, warm and supportive student-student relationships in the school class. Because the prevalence of victims of bullying was found to be negatively linked to student-student relationship quality and positively linked to class moral disengagement, both these socio-moral factors of the peer ecology of the school class should be addressed in moral education and bullying prevention. In their study of pre-service teachers' and in-service teachers’ attitudes towards bullying, Begotti et al. (2016) found that the perception of seriousness of different forms of bullying, empathy towards the victims, and likelihood to intervene, varied among the teachers. In relation to our findings, this points to a need for introducing the concept of moral disengagement in teacher education and to enhance student teachers' moral self-awareness and self- 
regulation as forthcoming professional teachers. They need to be prepared to identify and counteract moral disengagement both in themselves as well as among the students. Thus, a basic component in bullying prevention is teachers with high moral agency, and who develop and facilitate caring relationships in their everyday interactions with their students.

\section{References}

Atria, M., D. Strohmeier, and C. Spiel. 2007. "The Relevance of the School Class as Social Unit for the Prevalence of Bullying and Victimization.” European Journal of Developmental Psychology 4(4): 372-387. doi:

$10.1080 / 17405620701554560$

Bandura, A. 1986. Social Foundations of Thought and Action: A Social Cognitive Theory. Englewood Cliffs, NJ: Prentice-Hall.

Bandura, A. 1997. Self-Efficacy: The Exercise of Control. New York. Freeman and Company.

Bandura, A. 1999. "Moral Disengagement in the Perpetration of Inhumanities.” Personality and Social Psychology Review 3(3): 193-209. doi: 10.1207/s15327957pspr0303_3

Bandura, A. 2002. "Selective Moral Disengagement in the Exercise of Moral Agency.” Journal of Moral Education 31(2): 101-119. doi: 10.1080/0305724022014322

Begotti, T., M. Tirassa, and D. A. Maran. 2016. “School Bullying Episodes: Attitudes and Intervention in Pre-Service and In-Service Italian Teachers.” Research Papers in Education. doi: 10.1080/02671522.2016.1158857 
Bollmer, J. M., R. Milich, M.J. Harris, and M. A. Maras. 2005. “A Friend in Need: The Role of Friendship Quality as a Protective Factor in Peer Victimization. Journal of Interpersonal Violence 20(6): 701-712. doi: 0.1177/0886260504272897

Brechwald, W. A., and M. J. Prinstein. 2011. "Beyond Homophily: A Decade of Advances in Understanding Peer Influence Processes.” Journal of Research on Adolescence 21(1): 166-179. doi: 10.1111/j.1532-7795.2010.00721.x

Brown, B. B., and C. Klute, C. 2006. "Friendships, Cliques, and Crowds.” In Blackwell Handbook of Adolescence, edited by G. R. Adams and M. D. Berzonsky, 330348. Malden, MA: Blackwell.

Bru, E., P. Stephens, and T. Torsheim. 2002. “Students’ Perceptions of Class Management and Reports of Their Own Misbehavior.” Journal of School Psychology 40(4): 287-307. doi: 10.1016/S0022-4405(02)00104-8

Casas, J. A., R. Ortega-Ruiz, and R. Del Rey. 2015. "Bullying: The Impact of Teacher Management and Trait Emotional Intelligence.” British Journal of Educational Psychology 85(3). doi: 10.1111/bjep.12082

Corcoran, L., C. Mc Guckin. 2014. “Addressing Bullying Problems in Irish Schools and in Cyberspace: A Challenge for School Management. Educational Research 56(1): 48-64. Doi: 10.1080/00131881.2013.874150

Craig, W. M., and D. Pepler. 1997. “Observations of Bullying and Victimization in the School Yard.” Canadian Journal of School Psychology 13(2): 41-60. doi: $10.1177 / 082957359801300205$

Craig, W. M., D. Pepler, and R. Atlas. 2000. Observations of Bullying in the Playground and in the Classroom.” School Psychology International 21(1): 2236. doi: $10.1177 / 0143034300211002$ 
Crano, W. D. (2000). “Milestones in the Psychological Analysis of Social Influence.” Group Dynamics: Theory, Research, and Practice 4(1): 68-61. doi: 10.1037/1089-2699.4.1.68

Demaray, M. K., and C. K. Malecki. 2003. "Perceptions of the Frequency and Importance of Social Support by Students Classified as Victims, Bullies, and Bully/Victims in an Urban Middle School.” School Psychology Review 32(3): 471-489.

Diener, E. 1979. “Deindividuation, Self-Awareness, and Disinhibition.” Journal of Personality and Social Psychology 37(7): 1160-1171. doi: 10.1037/00223514.37.7.1160.

Doll, B., Song, S., and Siemers, E. 2004. “Classroom Ecologies that Support or Discourage Bullying. In Bullying in American Schools: A Social-Ecological Perspective on Prevention and Intervention, edited by D. L. Espelage and S. M. Swearer, 161-183. Mahwah, NJ: Lawrence Erlbaum Associates.

Donohue, K. M., K. E. Perry, and R. S. Weinstein. 2003. “Teachers’ Classroom Practices and Children’s Rejection by Their Peers.” Applied Developmental Psychology 24(1): 91-118. doi: 10.1016/S0193-3973(03)00026-1

Eliot, M., D. Cornell, A. Gregory, and X. Fan. 2010. "Supportive School Climate and Student Willingness to Seek Help for Bullying and Threats of Violence.” Journal of School Psychology 48(6): 533-553. Doi: 10.1016/j.jsp.2010.07.001

Espelage, D. L., and S. M. Swearer, ed. 2004. Bullying in American Schools: A SocialEcological Perspective on Prevention and Intervention. Mahwah, NJ: Lawrence Erlbaum Associates.

Espelage, D. L., and S. M. Swearer. 2010. “A Social-Ecological Model for Bullying Prevention and Intervention: Understanding the Impact of Adults in the Social 
Ecology of Youngsters.” In Handbook of Bullying in Schools: An International

Perspective, edited by S. R. Jimerson, S. M. Swearer, and D. L. Espelage, 6172. New York, NY: Routledge.

Flaspohler, P. D., J. L., Elfstrom, K. L., Vanderzee, and H. E. Sink. 2009. “Stand by Me: The Effects of Peer and Teacher Support in Mitigating the Impact of Bullying on Quality of Life.” Psychology in the Schools 46(7): 636-649. doi: 10.1002/pits.20404

Gifford-Smith, M., K. A. Dodge, T. J. Dishion, and J. McCord. 2005. "Peer Influence in Children and Adolescents: Crossing the Bridge from Developmental to Intervention Science.” Journal of Abnormal Child Psychology 33(3): 255-265. doi: 10.1007/s10802-005-3563-7

Gini, G., and T. Pozzoli. 2013. "Bullied Children and Psychosomatic Problems: A Meta-Analysis.” Pediatrics 132(4): 720-729. doi: 10.1542/peds.2013-0614 Gini, G., T. Pozzoli, and K. Bussey. 2015. “The Role of Individual and Collective Moral Disengagement in Peer Aggression and Bystanding: A Multilevel Analysis.” Journal of Abnormal Child Psychology 43(3): 441-452. doi: 10.1007/s10802-014-9920-7

Gini, G., T. Pozzoli, and S. Hymel. 2014. "Moral Disengagement among Children and Youth: A Meta-Analytic Review of Links to Aggressive Behavior.” Aggressive Behavior 40(1): 56-68. doi: 10.1002/ab.21502

Gregory, A., D. Cornell, X. Fan, P. Sheras, T-H.Shih, and F. Huang. 2010.

“Authoritative School Discipline: High School Practices Associated with Lower Bullying and Victimization.” Journal of Educational Psychology 102(2): 483496. doi: 10.1037/a0018562 
Hamre, B. K., R. C. Pianta, J. T. Downer, and A. J. Mashburn. 2008. “Teachers’ Perceptions of Conflict with Young Students: Looking Beyond Problem Behaviors.” Social Development 17(1): 115-136. doi: 10.1111/j.14679507.2007.00418.x

Haslam, N. 2006. “Dehumanization: An Integrative Review.” Personality and Social Psychology Review 10(3): 252-264. doi: 10.1207/s15327957pspr1003_4

Horton, P., S. Kvist Lindholm, and T. H. Nguyen. 2015. "Bullying the Meek: A Conceptualisation of Vietnamese School Bullying”. Research Papers in Education 30(5): 635-645. Doi: 10.1080/02671522.2015.1027728

Howes, C., C. E. Hamilton, and C. C. Matheson. 1994. “Children’s Relationships with Peers: Differential Associations with Aspects of the Teacher-Child Relationship”. Child Development 65(1): 253-263. doi: 10.1111/j.14678624.1994.tb00748.x

Hughes, J. N., T. A. Cavell, and T. Jackson. 1999. “Influence of Teacher-Student Relationship on Childhood Aggression: A Prospective Study.” Journal of Clinical Child Psychology 28(2): 173-184. doi: 10.1207/s15374424jccp2802_5

Hughes, J. N., T. A. Cavell, and V. Wilson. 2001. "Further Support for the Developmental Significance of the Quality of the Teacher-Student Relationship.” Journal of School Psychology 39(4): 289-301.

Hughes, J. N., H. I. Myung, and S. E. Wehrly. 2014. "Effect of Peer Nominations of Teacher-Student Support at Individual and Classroom Level on Social and Academic Outcomes.” Journal of School Psychology 52(3): 309-322.

Hymel, S. 1986. "Interpretations of Peer Behavior: Affective Bias in Childhood and Adolescence.” Child Development 57(2): 431-445. 
Hymel, S., K. A. Schonert-Reichl, R. A. Bonanno, T. Vaillancourt, and N. Rocke Henderson. 2010. “Bullying and Morality”. In Handbook of Bullying in Schools: An International Perspective, edited by S. R. Jimerson, S. M. Swearer, and D. L. Espelage, 101-118. New York, NY: Routledge.

Isakson, K., and P. Jarvis. 1999. “The Adjustment of Adolescence during the Transition to High School: A Short-Term Longitudinal Study. Journal of Youth and Adolescence 28(1): 1-26.

Jennings, P. A., and M. T. Greenberg. 2009. ”The Prosocial Classroom: Teacher Social and Emotional Competence in Relation to Student and Classroom Outcomes.” Review of Educational Research 79(1): 491-525.

Juvonen, J., and A. Galvan. 2008. “Peer Influence in Involuntary Social Groups: Lessons from Research on Bullying.” In Peer influence processes among youth, edited by M. Prinstein and K. Dodge, 225-244. New York: Guilford Press.

Lucas-Molina, B., A. A. Williamson, R. Pulido, and A. Pérez-Albéniz. 2015. "Effects of Teacher-Student Relationships on Peer Harassment: A Multilevel Study.” Psychology in the Schools 52(3): 1520-6807.

Maldonado-Carreño, C., and E. Votruba-Drzal. 2011. “Teacher-Child Relationships and the Development of Academic and Behavioral Skills during Elementary School: A Within- and Between-Child Analysis.” Child Development 82(2): $601-616$.

Matsumura, L. C., S. C. Slater, and A. Crosson. 2008. “Classroom Climate, Rigorous Instruction and Curriculum, and Students' Interactions in Urban Middle Schools.” Elementary School Journal 108(4): 293-312.

Maunder, R. E., A. Harrop, and A. J. Tattersall. 2010. "Pupil and Staff Perceptions of Bullying in Secondary Schools: Comparing Behavioural Definitions and their 
Perceived Seriousness. Educational Research 52(3): 263-282. doi: $10.1080 / 00131881.2010 .504062$

Noddings, N. 2012. “The Caring Relation in Teaching.” Oxford Review of Education 38(6): 771-781. doi: 10.1080/03054985.2012.745047

Nucci, L. P., and D. Narvaez, eds. 2008. Handbook of Moral and Character Education. New York, NY: Routledge.

O’Brien, C. 2011. “Young People’s Comparisons of Cross-Gender and Same-Gender Bullying in British Secondary Schools. Educational Research 53(3): 257-301. doi: 10.1080/00131881.2011.598658

O’Connell, P., D. Pepler, and W. Craig. 1999. “Peer Involvement in Bullying: Insight and Challenges for Observation.” Journal of Adolescence 22(4): 437-452.

Olweus, D. 2010. “Understanding and Researching Bullying: Some Critical Issues.” In Handbook of Bullying in Schools: An International Perspective, edited by S. R. Jimerson, S. M. Swearer, and D. L. Espelage, 9-33. New York, NY: Routledge.

Osbeck, C., A-S. Holm, and I. Wernersson. 2003. Kränkningar i Skolan: Förekomst, Former och Sammanhang [Harassment in School: Frequency, Forms, and Context]. Göteborg: Göteborgs universitet.

Perren, S., and F. D. Alsaker. 2006. "Social Behavior and Peer Relationships of Victims, Bully-Victims, and Bullies in Kindergarten.” Journal of Child Psychology and Psychiatry 47(1): 45-57. doi: 10.1111/j.14697610.2005.01445.x

Perren, S., and R. Hornung. 2005. “Bullying and Delinquency in Adolescence: Victims' and Perpetrators’ Family and Peer Relations” Swiss Journal of Psychology 64 (1): 51-64. doi: 10.1024/1421-0185.64.4.51 
Pozzoli, T., G. Gini, and A. Vieno. 2012. “Individual and Class Moral Disengagement in Bullying among Elementary School Children.” Aggressive Behavior 38(5): 378-388. doi: 10.1002/ab.21442

Raskauskas, J. L., J. Gregory, S. T. Harvey, F. Rifshana, and I. M. Evans. 2010. "Bullying among Primary School Children in New Zealand: Relationships with Prosocial Behaviour and Classroom Climate.” Educational Research 52(1): 113.

Rey, R., B., A. L. Smith, J. Yoon, C. Somers, and D. Barnett. 2007. “Relationships between Teachers and Urban African American Children.” School Psychology International 28(3): 346-364.

Richard, J. F., B. H. Schneider, and P. Mallet. 2011. "Revisiting the Whole-School Approach to Bullying: Really Looking at the Whole School.” School Psychology International 33(3): 263-284.

Rigby, K. 2000. “Effects of Peer Victimization in Schools and Perceived Social Support on Adolescent Well-Being.” Journal of Adolescence 23(1): 57-68. doi: 10.1006/jado.1999.0289

Roland, E., and D. Galloway. 2002. “Classroom Influences on Bullying.” Educational Research 44(3): 299-312.

Roorda, D. L., H. M. Y. Koomen, J. L. Spilt, and F. J. Oort. 2011. “The Influence of Affective Teacher-Student Relationships on Students' School Engagement and Achievement: A Meta-Analytic Approach.” Review of Educational Research 81(4): 493-529.

Rosenfeld, L. B., J. M. Richman, and G. L. Bowen. 1998. “Social Support Networks and School Outcomes: The Centrality of the Teacher." Child and Adolescent Social Work Journal 17(3): 204-226. 
Saarento, S., and C. Salmivalli. 2015. "The Role of Classroom Peer Ecology and Bystanders’ Responses in Bullying.” Child Development Perspectives 9(4): 201205. doi: $10.1111 /$ cdep.12140

Sabol, T. J., and R. Pianta. 2012. "Recent Trends in Research on Teacher-Child Relationships.” Attachment \& Human Development 14(3): 213-231.

Salmivalli, C. 2010. “Bullying and the Peer Group: A Review.” Aggression and Violent Behavior 15(2): 112-120.

Salmivalli, C., and M. Voeten. 2004. "Connections between Attitudes, Group Norms, and Behaviour in Bullying Situations. International Journal of Behavioral Development 28(3): 246-258.

Sarkova, M., M. Bacikova-Sleskova, A. Madarosova Geckova, Z. Katreniakova, W. van den Heuvel, and J. P. van Dijk. 2014. “Adolescents’ Psychological Well-Being and Self-Esteem in the Context of Relationships at School. Educational Research 56(4): 367-378. doi: 10.1080/00131881.2014.965556

Schmidt, M. E., and C. L. Bagwell. 2007. "The Protective Role of Friendships in Overtly and Relationally Victimized Boys and Girls.” Merrill-Palmer Quarterly 53(3): 439-460. doi: 10.1353/mpq.2007.0021

Solberg, M. E., and D. Olweus. 2003. "Prevalence Estimation of School Bullying with the Olweus Bully/Victim Questionnaire.” Aggressive Behavior 29(3): 239-268. doi: 10.1002/ab.10047

Solomon, D., M. Watson, V. Battistich, E. Schaps, and K. Delucchi, (1996). “Creating Classrooms that Students Experience as Communities.” American Journal of Community Psychology 24(6): 719-748.

Stefanek, E., D. Strohmeier, R. van de Schoot, and C. Spiel. 2011. "Bullying and Victimization in Ethnically Diverse Schools: Risk and Protective Factors on 
Individual and Class Level.” International Journal of Developmental Science 5(1-2): 73-84. doi: 10.3233/DEV-2011-11073

Teräsahjo, T., and C. Salmivalli. 2003. “'She is Not Actually Bullies’: The Discourse of Harassment in Student Groups.” Aggressive Behavior 29(2): 134-154. doi: 10.1002/ab.10045

Thornberg, R. 2015. “School Bullying as a Collective Action: Stigma Processes and Identity Struggling.” Children \& Society 29(4): 310-320. doi: 10.1111/chso.12058

Thornberg, R., and T. Jungert. 2013. “Bystander Behavior in Bullying Situations: Basic Moral Sensitivity, Moral Disengagement and Defender Self-Efficacy.” Journal of Adolescence 36: 475-483. doi: 10.1016/j.adolescence.2013.02.003

Thornberg, R., U. Thornberg, R. Alamaa, and N. Daud. 2016. “Children’s Conceptions of Bullying and Repeated Conventional Transgressions: Moral, Conventional, Structuring, and Personal-Choice Reasoning.” Educational Psychology 36(1): 95-111. doi: 10.1080/01443410.2014.915929

Thornberg, R., L. Wänström, and T. Pozzoli. 2016. “Peer Victimisation and Its Relation to Class Relational Climate and Class Moral Disengagement among School Children.” Educational Psychology, doi: 10.1080/01443410.2016.1150423

Varjas, K., C. C. Henrich, and J. Meyers. 2009. “Urban Middle School Students’ Perceptions of Bullying, Cyberbullying, and School Safety.” Journal of School Violence 8(2): 159-176. doi: 10.1080/15388220802074165

Wentzel, K. R. 2015. “Socialization in school settings.” In Handbook of Socialization: Theory and Research, edited by J. E. Grusec, \& P. D. Hastings, 251-275. New York, NY: Guilford Press. 
Wubbels, T., M. Brekelmans, P. den Brok, L. Wijsman, T. Mainhard, \& J. van Tartwijk. 2015. “Teacher-Student Relationships and Classroom Management.” In Handbook of Classroom Management ( ${ }^{\text {nd }}$ ed.), edited by E. T. Emmer and E. J. Sabornie, 363-386. New York: Routledge. 
Table 1. Correlations, means, standard deviations, and minimum and maximum observations at class level $(\mathrm{N}=43)$.

\begin{tabular}{lllllllll}
\hline & 1 & 2 & 3 & 4 & $\mathrm{M}$ & SD & Min & Max \\
\hline 1. Teacher-child relationships & - & $.65^{* * *}$ & -.09 & $-.37^{*}$ & 3.45 & .24 & 2.92 & 3.83 \\
2. Peer relationships & & - & $-.33^{*}$ & $-.61^{* * *}$ & 3.15 & .33 & 2.22 & 3.85 \\
3. Class moral disengagement & & & - & $.61^{* * *}$ & 1.31 & .19 & 1.01 & 1.84 \\
4. Proportion of victims & & & & - & .13 & .11 & .00 & 0.61 \\
\hline
\end{tabular}

Note. ${ }^{*} p<.05,{ }^{* *} p<.01, * * * p<.001$ 
Figure 1: The final path model (class level)

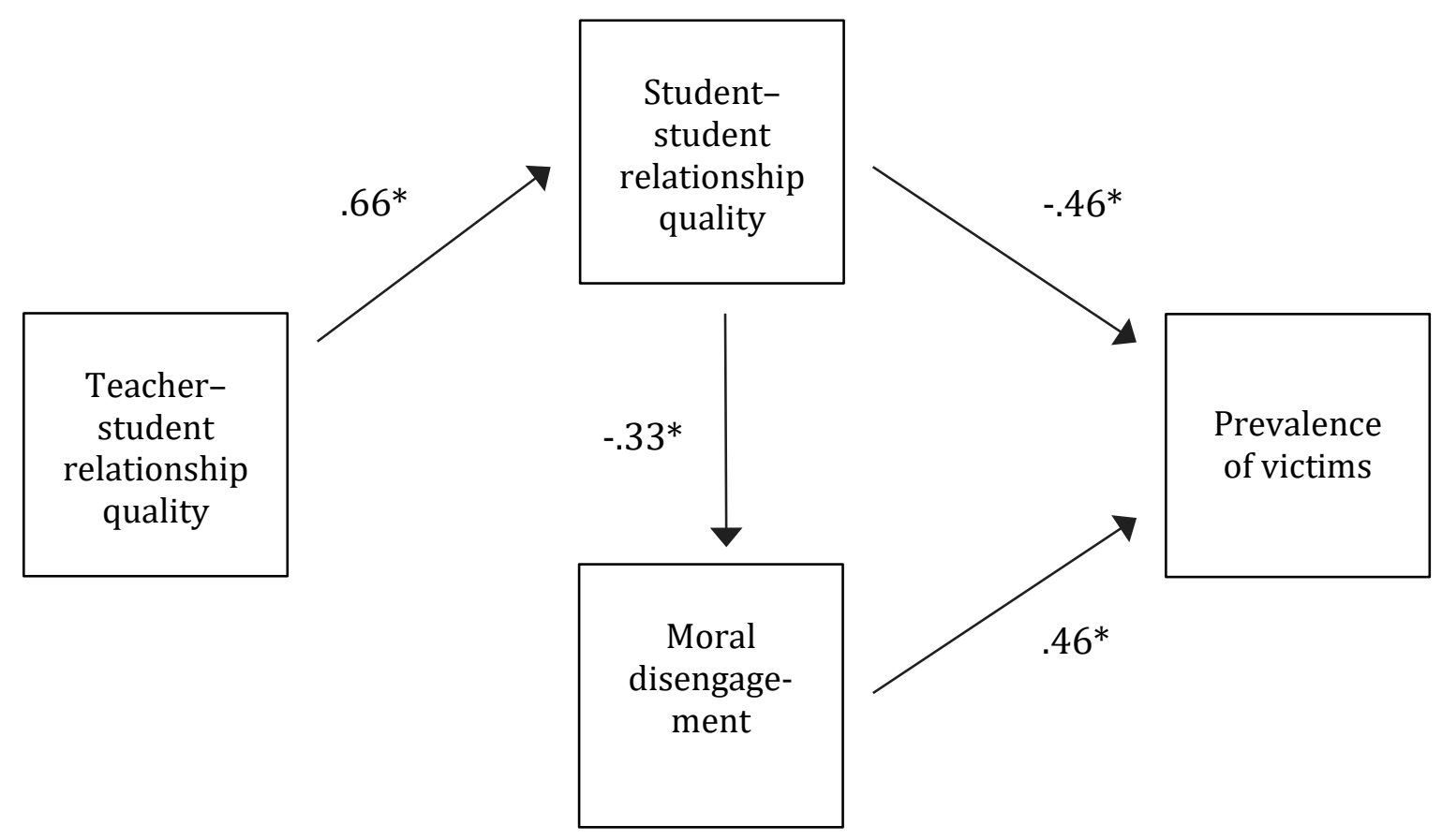

